\title{
Comment on: Definitive tests for dengue feVer: When AND Which ShOULd I USE?
}

Singapore Med J 2018; 59(1): 60 https://doi.org/10.11622/smedj.2018008

Dear Sir,

We read the article entitled "Definitive tests for dengue fever: when and which should I use?" with great interest. Chan et al wrote that "Viral detection diagnostic methods such as NS1 antigen assays are generally used within the first week of illness onset, whereas dengue serology testing is most appropriate after that time frame. Locally available rapid point-of-care tests, which include both assays in one convenient test kit, can enhance dengue diagnosis in an endemic setting."(1) As a matter of fact, dengue fever is presently a public health problem in Southeast Asia and early diagnosis is the main determinant of success in case management. ${ }^{(2)}$ We would hereby like to share our ideas and experience on this issue.

A previous report has discussed the use of immunodiagnosis in Thailand, a country with high prevalence of dengue. ${ }^{(3)}$ Kowitdamrong et al concluded that "Rapid and accurate detection of dengue lgM [immunoglobulin M] has become more useful because only single serum is required. A request for dengue IgM should be done after Day 5 of illness."(3) In reality, due to the high incidence of disease, the main basic diagnostic approach to dengue in Thailand is usually clinical diagnosis, and the simple tourniquet test has proven useful. ${ }^{(4)}$ Since the definitive diagnosis does not alter the guideline for dengue management, most infections in Thailand are usually diagnosed based on clinical features and the patient's response to standard dengue fluid-replacement therapy. ${ }^{(3)}$

Yours sincerely,

Beuy loob ${ }^{1}$, Viroj Wiwanikit ${ }^{2}$

${ }^{1}$ Sanitation 1 Medical Academic Center, Bangkok, Thailand, ${ }^{2}$ Dr DY Patil University, Maharashtra, India. beuyjoob@hotmail.com

\section{References}

1. Chan HBY, How $\mathrm{CH}, \mathrm{Ng}$ CW. Definitive tests for dengue fever: when and which should I use? Singapore Med I 2017; 58:632-5.

2. Wiwanitkit V. Dengue fever: diagnosis and treatment. Expert Rev Anti Infect Ther 2010; 8:841-5.

3. Kowitdamrong E, Thammaborvorn R, Semboonlor L, Mungmee V, Bhattarakosol P. Detection of dengue HI and IgM antibody: is it diagnostically useful? when and how? J Med Assoc Thai 2001; 84 Suppl 1:S148-54.

4. Wiwanitkit $\mathrm{V}$. The tourniquet test is still a good screening tool for dengue illness. Trop Doct 2005; 35:127-8. 